\title{
PENSAMENTO E LINGUAGEM: PERCURSO PIAGETIANO DE INVESTIGAÇÃO
}

\author{
Adrián Oscar Dongo Montoya
}

\begin{abstract}
RESUMO. O objetivo deste trabalho é mostrar o percurso da investigação de Piaget sobre as origens e as relações existentes entre a linguagem e o pensamento. Para isso, analisaremos, num primeiro momento, os trabalhos iniciais desse autor sobre a evolução e socialização do pensamento e da linguagem na criança, destacando a explicação exógena dos seus progressos. Num segundo momento, analisaremos as pesquisas realizadas por ele nas décadas de trinta e quarenta do século XX sobre as origens sensório-motoras do pensamento e da linguagem, destacando a explicação endógena dos seus progressos. Num terceiro momento, analisaremos estudos psicolingüísticos junto a crianças normais e crianças portadoras de deficiências, os quais confirmarão a pertinência da tese de Piaget sobre as origens do pensamento e da linguagem. Finalmente, salientaremos algumas teses conclusivas desse autor, a propósito das críticas às teorias empiristas e positivistas contemporâneas, com vistas a diferenciar a singularidade da sua formulação teórica.
\end{abstract}

Palavras-chave: pensamento e linguagem, percurso piagetiano, continuidade com reconstrução.

\section{LANGUAGE AND THOUGHT: PIAGET'S COURSE OF INVESTIGATION}

\begin{abstract}
This study aims at discussing Piaget's course of investigation about the origins and the existent relationship between language and thought. In order to meet our goals, firstly, we will analyze the author's initial works about the evolution and socialization of children's thought and language, emphasizing the exogenous explanation of their progress. Secondly, we will investigate the research studies carried out by Piaget, during the 30's and 40's decades, about the motor-sensory origins of thought and language, focusing the endogenous explanation of their progress. Thirdly, we will analyze the psycholinguistic studies related to normal and disabled children, which confirms Piaget's thesis relevance, concerning the origins of thought and language. Finally, we will point out some of the author's conclusive theses, based on his theoretical framework, concerning the critiques to contemporary empirical and positivist theories.
\end{abstract}

Key words: thought and language, Piaget's course, continuity with reconstruction.

As pesquisas de Piaget sobre as origens do pensamento e da linguagem são objeto de críticas, interrogações e leituras parciais que exigem maiores esclarecimentos. As questões que exigem maiores esclarecimentos, ao nosso ver, são as seguintes: existe mudança de perspectiva entre as pesquisas feitas na década de 1920 e aquelas feitas nas duas décadas seguintes? Se tal mudança existe, qual a razão e o significado dela? Essa mudança consistirá no abandono da perspectiva da explicação social para abraçar a perspectiva da explicação individual ou significará, pelo contrário, a possibilidade de integração de ambas as formas de explicação? A explicação feita por Piaget sobre as condições e processos que possibilitam a aquisição da linguagem e da função simbólica, como alguns dos seus críticos e comentadores afirmam (Banks-Leite, 1997; Bronckart, 2000), permanece lacunar? Quais as implicações teóricas e epistemológicas das investigações feitas por ele sobre a origem sensório-motora do pensamento e da função simbólica?

É importante destacar que o debate atual - no qual é preciso situar o trabalho de Piaget - sobre a explicação das origens da linguagem e do pensamento não é aquele da falsa alternativa do determinismo social ou do determinismo biológico, nem aquele dos reducionismos psicológicos e sociológicos. $\mathrm{O}$ problema fundamental a enfrentar é a questão de saber como as novas formas de ação humana se organizam a partir de formas anteriores (reflexos e esquemas sensório-motores) e como nesse processo participam fatores endógenos e exógenos. É nesse sentido que

\footnotetext{
* Mestre em Psicobiologia, Doutor em Neurociências e Comportamento, Professor Associado ao Departamento de Psicologia Geral e Análise do Comportamento da Universidade Paulista Julio Mesquita Filho, Marília-SP. Pós-doutorando no Departamento de Psicologia e Educação da Universidade de São Paulo.
} 
precisamos saber sobre as interações entre as estruturas orgânicas, psicológicas e sociais, assim como as complementaridades entre as explicações biológicas, psicológicas e sociológicas.

A nossa conjetura sobre o percurso da pesquisa de Piaget em relação às origens e desenvolvimento da linguagem e do pensamento é que existe uma evolução do seu pensamento científico, não no sentido de simples ruptura com o passado nem de simples prolongamento, mas de superação no sentido hegeliano do termo: continuidade com reconstrução ("aufhebung"), pois as conquistas da primeira fase serão incorporadas num sistema maior, como conseqüência de reconstruções em função de novas descobertas.

Numa primeira aproximação, podemos afirmar que, nas pesquisas iniciadas por Piaget na década do 1920, as conquistas conceituais realizadas pela criança são explicadas por ele em função da socialização lingüística e de interações sociais. Já nas pesquisas realizadas nas décadas de 1930 e 1940, em razão da descoberta de estruturas de conhecimento pré-verbais assim como de novos mecanismos internos de formação (assimilação recíproca, coordenação de esquemas, reação circular, etc), a explicação das origens da linguagem e do pensamento é buscada na interiorização do esquematismo sensório-motor da criança; portanto, na atividade construtiva do sujeito.

É importante lembrar que as primeiras doutrinas de formação dos mecanismos mentais e das condutas individuais insistiram em reduzir ao aspecto social tudo o que aquelas comportam de psiquismo superior do indivíduo. Entretanto, à medida que a ciência psicológica conseguiu dissociar melhor aquilo que é comum e geral a todos os indivíduos - como é o caso das estruturas mentais - e aquilo que cada indivíduo pode inventar ou diferenciar no curso das suas especializações pessoais, os termos do problema têm-se modificado profundamente. Assim, segundo as tendências atuais, a questão não é tanto estabelecer até que ponto o indivíduo é socializado (pois ele o é desde o seu nascimento e segundo modos bastante diversos), mas discernir se, entre as estruturas orgânicas e as estruturas sociais - mas não exclusivamente sociais -, existem estruturas "gerais" ou comuns a todos os indivíduos membros da sociedade e explicar as interações entre as realidades - estruturas - biológicas, psicológicas e sociais.

Se a análise das relações entre a linguagem e o pensamento realiza-se levando em conta essas novas perspectivas, o modo de explicação dos fatores endógenos e exógenos torna-se mais integrativo e mais diferenciado. Sobre essas novas bases, portanto, a hipótese da interação e solidariedade entre a linguagem e o pensamento assume um sentido verdadeiramente novo, pois supera as determinações unilaterais da ação individual e da ação coletiva.

\section{PESQUISAS INICIAIS DE PIAGET SOBRE O PENSAMENTO E A LINGUAGEM}

Não há dúvida de que Piaget, desde o começo, teve como objetivo maior resolver os grandes problemas epistemológicos, isto é, explicar como o sujeito conhece e fornece explicações cada vez mais objetivas e mais abrangentes sobre o mundo. Para isso teve que realizar pesquisas psicogenéticas sobre as origens e a estruturação progressiva do conhecimento e, nesse sentido, investigar o papel da lógica e da linguagem.

É nesse contexto de preocupação teórica que se realizam os primeiros estudos sobre o desenvolvimento do pensamento e da linguagem da criança. A passagem do egocentrismo infantil para a objetividade e para o pensamento lógico encontra-se, segundo esse autor, estreitamente relacionada à linguagem socializada, isto é, à linguagem cujos termos e conceitos são compartilhados por todos os membros do grupo, a qual possui uma estrutura lógica.

Muitos autores já salientaram a natureza desse período de pesquisa, no sentido de que esses primeiros trabalhos enfatizaram questões de ordem "lógicoverbal" ou "lógico-conceitual", para apreender o progresso das características do pensamento infantil, que é essencialmente egocêntrico.

\section{Pensamento egocêntrico $\longrightarrow$ pensamento lógico (Pensamento socializado) \\ Linguagem egocêntrica $\longrightarrow$ linguagem lógica (Linguagem socializada)}

$\mathrm{Na}$ perspectiva da explicação do progresso, nessa fase, as pesquisas de Piaget $(1923,1924)$ mostram que os fatores sociais e culturais são aqueles que promovem o desenvolvimento do pensamento. Assim, quando ele se refere à sucessão evolutiva do pensamento "autístico" (individual e incomunicável) para o pensamento "dirigido" (socializada, orientada pela adaptação progressiva dos indivíduos uns aos outros), o progresso é atribuído à ação do meio social e da linguagem. Explica assim que a oposição entre as duas formas de pensamento

(...) obedece em grande parte ao fato de que a inteligência, precisamente porque se socializa progressivamente, procede cada vez mais por 
conceitos, em virtude da linguagem que liga $o$ pensamento às palavras, enquanto $o$ autismo, precisamente porque permanece individual, continua ligado à representação por imagens, à atividade orgânica e aos movimentos. $\mathrm{O}$ fato de contar seus pensamentos, de transmiti-los aos outros, ou de calar ou falar somente consigo mesmo, deve ter, portanto, uma importância primordial na estrutura e funcionamento do pensamento em geral, da lógica da criança em particular. (1999, p.43)

Não de pode deixar de destacar que a explicação da evolução se encontra fundamentalmente no processo de socialização do pensamento, o qual implica uso de conceitos provenientes da linguagem verbal que liga o pensamento às palavras.

Os argumentos mais taxativos da ação da interação social sobre a evolução do pensamento se encontram na análise do estágio da discussão verdadeira da criança:

Como dissemos há pouco, se admitirmos que há uma correlação entre a atividade da criança e o seu pensamento, é evidente que é o hábito da discussão que produz a necessidade de elaborar a unidade, de sistematizar as próprias opiniões. É o que Janet e Tarde demostraram a propósito da psicologia da discussão em geral. Eles mostraram-nos que toda reflexão é produto de uma discussão interior, e de uma discussão que leva a uma conclusão, como se o indivíduo repetisse, diante de si próprio, a atitude que adotara para com os outros. Nossas pesquisas confirmaram esta maneira de ver (1999, p.117, grifo do autor).

Nessa mesma obra, quando constata que a précausalidade na criança tende a desaparecer na mesma idade em que desaparece o egocentrismo (sete a oito anos), diz que em toda explicação causal há um esforço de adaptação ao mundo exterior, um esforço de objetivação e de despersonalização do pensamento. Quando constata que nos hábitos lógicos há um esforço de coerência interna e de direção no pensamento, que não é inerente ao pensamento primitivo, mas uma conquista progressiva da razão, o progresso é atribuído ao papel decisivo dos hábitos de discussão.

Ainda aqui o egocentrismo do pensamento é um obstáculo real à aquisição dessa necessidade de implicação ou de sistematização lógica. Obstáculo direto, porque todo pensamento egocêntrico é, por sua estrutura, intermediário entre $\mathrm{o}$ pensamento autístico, que é não dirigido, isto é, flutua ao sabor dos caprichos (como no devaneio), e a inteligência dirigida. $\mathrm{O}$ egocentrismo obedece, ainda, ao bel-prazer do eu, mais do que à sua lógica impessoal. Obstáculo indireto, igualmente, pois somente os hábitos de discussão e de vida social levam à lógica, e o egocentrismo, precisamente, torna impossível esses hábitos (1999, p 275-6).

Nota-se que, apesar de Piaget procurar fundamentar uma teoria interacionista da formação do pensamento e da linguagem, escapa-lhe a explicação psicológica endógena da evolução do pensamento, pois recorre simplesmente à interação social como elemento explicativo. Noutras palavras, a aquisição da linguagem e a interação social (troca e cooperação entre indivíduos) estariam explicando, nessa época, a evolução do pensamento e da linguagem.

Nesse ponto, Vygotsky destaca a coincidência de sua hipótese com a hipótese explicativa de Piaget daquela época, pois para ele o desenvolvimento da lógica na criança é uma função direta de sua fala socializada.
Basicamente, o desenvolvimento da fala interior depende de fatores externos: o desenvolvimento da lógica na criança, como os estudos de Piaget demonstram, é uma função direta de sua fala socializada. O crescimento intelectual da criança depende de seu domínio dos meios sociais do pensamento, isto é, da linguagem (Vygotsky, 1991 p.44).

Nesse período, então, é clara a tese de Piaget sobre a importância decisiva e explicativa da linguagem na formação do pensamento lógico, ao passo que processos e mecanismos internos e mais profundos ("coordenação de esquemas de ação", "reação circular", "interiorização de esquemas", "autoregulação", "equilibração", etc.), que explicariam a construção de esquemas conceptuais, ainda não estavam formulados. Nesse sentido, pode-se dizer que a tese Piaget, nesse período, representa um reducionismo social.

Essa nossa conjetura sobre o pensamento inicial de Piaget e a mudança posterior de perspectiva sobre as origens do pensamento e da linguagem encontra-se confirmada na passagem de um artigo, redigido por ele mesmo na década de sessenta (1969), a propósito do reducionismo social: 
Tal modo de explicação se encontra atualmente em todos os campos da afetividade elementar (psicanálise chamada culturalista: E. Fromm, etc.) e das condutas em geral (R. Benedict; M. Mead, etc.) até as reações cognitivas (desde $\mathrm{M}$. Baldwin e P. Janet, até os trabalhos de Vygotsky e Luria sobre o papel da linguagem, passando por nossas próprias obras iniciais) e as condutas propriamente sociais (sociometria, etc.) (Piaget, 1969, p.133, grifo do autor).

O princípio utilizado pelas concepções reducionistas, segundo Piaget (1969), é o mesmo: quando um comportamento novo vem enriquecer os precedentes, no decurso do desenvolvimento, isso seria devido menos a uma construção interna (endógena) do que a um resultado das próprias interações da vida social. Por exemplo, quando se explica o aparecimento da reflexão, invocando a conduta social da deliberação - assim como da sua interiorização - sobre a forma de discussão consigo mesmo, há uma construção de conduta nova, mas a partir do plano interindividual ou coletivo. A novidade de tal conduta - a reflexão - é reduzida, portanto, ao mecanismo exterior, e não deriva de uma construção interna, a partir das condutas de níveis anteriores.

Os processos e mecanismos internos de formação do pensamento serão analisados no item seguinte, quando da aquisição dos primeiros esquemas verbais e dos "pré-conceitos", depois de serem esclarecidas as suas raízes sensório-motoras (nas coordenações gerais da ação).

\section{PESQUISAS REALIZADAS POR PIAGET NAS DÉCADAS DO TRINTA E DO QUARENTA.}

\section{Origens do pensamento na inteligência pré-verbal}

As pesquisas que se desenvolveram nas décadas do trinta e quarenta tiveram como propósito mostrar a origem do pensamento nas coordenações gerais das ações, e a aquisição da linguagem, no exercício da função simbólica.

Os domínios nos quais são estudadas as origens do pensamento e da representação mental são aqueles da coordenação dos esquemas sensório-motores que se prolongam em conceitos e dos mecanismos imitativos que se prolongam em imagem mental.

No que diz respeito às origens do pensamento na coordenação das ações, a principal pesquisa realizada por Piaget sobre esse assunto encontra-se na obra "O Nascimento da Inteligência na Criança" (1936). Nessa pesquisa, analisa o exercício dos primeiros esquemas inatos (reflexos motores e perceptivos) que se prolongam nos primeiros esquemas e coordenações adquiridos (sucção do dedo, busca visual de um objeto audível, preensão dos objetos vistos, etc.) através de assimilação recíproca.

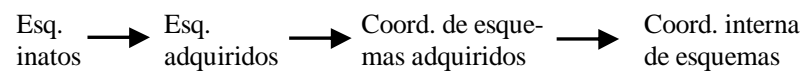

Através de novas assimilações recíprocas e "reações circulares secundárias", a criança, consegue dissociar e coordenar esquemas-fins e esquemas-meios na solução de problemas que implicam obstáculos interpostos aos seus interesses e desejos (terceira fase). Como conseqüência disso se iniciam os primeiros atos intencionais e inteligentes.

A coordenação de esquemas-meios e esquemasfins (quarta fase) carateriza uma atividade intencional e inteligente propriamente dita, pois a criança se coloca antecipadamente um propósito a alcançar e em função disso utiliza um esquema conhecido como instrumento necessário. É importante salientar que a natureza dessa coordenação denuncia não uma ligação qualquer, aleatória ou associativa, mas uma ligação implicativa isomorfa às futuras ligações lógicas, produto de uma assimilação recíproca dos esquemas em jogo, significando, assim, a assimilação recíproca, a integração de dois sistemas não apenas fundidos, como nas fases iniciais (segunda e terceira), mas diferenciados pelo sujeito.

A quinta fase da inteligência sensório-motora exprime um maior aprimoramento dessa coordenação, na medida em que a criança se torna capaz de descobrir e criar meios de solução por experimentação ativa. Assim, a criança consegue variar, intencionalmente, os meios a serem empregados em função dos fins a serem alcançados. Entretanto, como poderá ser observado na fase seguinte, o objetivo a ser alcançado não se faz ainda através de uma premeditação mental, mas, somente por esquemas motores e perceptivos que atuam sucessivamente.

A mobilidade e complexidade da coordenação de esquemas sensório -motores alcançados até então abrem novas possibilidades para uma coordenação de esquemas já não mais sucessivos e atuantes diretamente sobre os objetos externos, mas, ao contrário daqueles, interiorizados e combinados mentalmente. Assim, na sexta fase da inteligência sensório-motora, perante obstáculos infranqueáveis pelos procedimentos anteriormente conhecidos, a criança inventa soluções através de manobras ou operações simplesmente mentais. Desse modo, os esquemas anteriores são evocados para agir sobre os objetos, e essa evocação (ação interior de esquemas) se produz tendo como apoio símbolos ainda materiais 
(gestos imitativos) que se reportam a ações e objetos particulares.

Desse modo, o acabamento evolutivo da inteligência sensório-motora significa ao mesmo tempo o começo de sua interiorização, de tal modo que o esquematismo sensório-motor, reconstruindo-se, se prolongará nas futuras estruturas conceituais.

Nessa última fase, pode-se constatar também a formação simultânea dos significantes simbólicos, na forma dos gestos imitativos, os quais se prolongarão, transformando-se nas futuras imagens mentais.

\section{Origens da imagem mental na imitação sensório- motora}

A investigação sobre as origens sensório-motoras da imagem mental revela que ela resulta de um longo processo evolutivo da atividade imitativa, pólo de acomodação da inteligência. A pesquisa sobre a "Gênese da Imitação" (1935, 1945) mostra que essa atividade, desde os primeiros meses de vida da criança, evolui progressivamente na direção da imitação diferida, e esta, na direção da imagem mental. A função da imitação é, desde o começo, reproduzir ou figurar os caracteres particulares dos objetos, cujo desenvolvimento ocorre por influência do esquematismo sensório-motor e, a seguir, pelo esquematismo conceptual.

Como mostramos em trabalhos anteriores (Dongo Montoya, 1998a, 1998b, 2005), o nascimento da imagem, para Piaget, está atrelado ao nascimento do pensamento enquanto coordenação interna de esquemas, de tal maneira que até mesmo o desenvolvimento futuro de cada um desses dois elementos depende das suas relações recíprocas e indissolúveis: o primeiro (o pensamento) é fonte de mobilidade e de transformação e, esta última (a imagem) é fonte de figuração simbólica. Esse processo construtivo evidencia que não há nada de lacunar na explicação da função simbólica, por parte de Piaget, como alguns dos seus críticos insinuam; pelo contrário, os novos dados experimentais e a própria consistência explicativa mostram que há transformações progressivas, que envolvem reconstruções estruturais e continuidade funcional, no acabamento e no subseqüente desenvolvimento dessa função.

Assim, o duplo processo de interiorização da coordenação dos esquemas sensório-motores e da atividade imitativa é condição prévia para a constituição da função simbólica, isto é, da capacidade do sujeito de diferenciar significantes de significados. A imagem mental se constitui como significante que se reporta a uma situação ou a um objeto particular, sem esquecer que esse objeto também está relacionado a um esquema conceptual ou pré-conceptual. O símbolo lúdico implica também diferenciação de um significante (gesto ou objeto exterior) que representa um significante (objeto ausente), o qual é reportado por uma imagem. $\mathrm{O}$ desenho, enquanto figuração gráfica, reporta-se a um objeto ausente, mediado pela imagem que o sujeito constitui desse objeto. A linguagem, enquanto sistema de signos, implica significantes (gestos ou palavras articuladas) que se reportam a objetos mediados por conceitos ou "pré-conceitos", os quais se apóiam, sobretudo nas fases inicias, nas imagens mentais.

A aquisição da linguagem encontra-se, portanto, atrelada à constituição da capacidade humana de representar, isto é, de diferenciar significantes e significados, e por isso, ao exercício da função simbólica.

Isso não significa que a linguagem, uma vez adquirida, possa contribuir, decididamente, em troca, para a evolução da função simbólica em seu conjunto e particularmente para a evolução do pensamento conceptual.

\section{Transição da inteligência sensório-motora para a inteligência conceitual}

$\mathrm{Na}$ pesquisa sobre a transição dos esquemas sensório-motores para os esquemas conceptuais, Piaget (1945) mostra que os primeiros "esquemas verbais" da criança refletem o uso da linguagem, a qual se reporta a objetos exteriores assimilados em função dos esquemas sensório-motores em via de interiorização ou de conceptualização. "A denominação, como já se verificou pelas introduções precedentes, não é a simples atribuição de um nome, mas o enunciado de uma ação possível: a palavra se limita quase a traduzir, neste nível, a organização de esquemas sensóriomotores que poderiam passar sem ela" (Piaget, 1978, p.285).

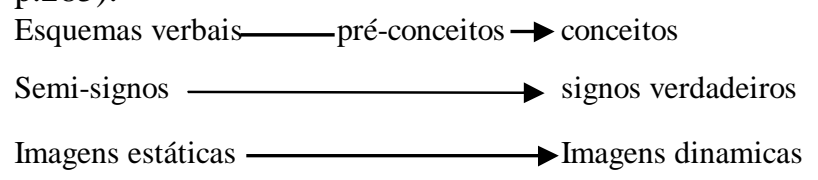

Continuidade com reconstrucão

É evidente que a linguagem, nesse nível inicial, participa no processo de socialização do pensamento, visto que permite trocar informações e colocar em correspondência pontos de vista, e nesse sentido possibilita o processo de conceptualização. Entretanto, esse processo não é de uma via somente, pois ele possibilita, reciprocamente, o desenvolvimento da 
competência lingüística. Sobre isso, Piaget assim se manifesta:

\begin{abstract}
Mas é claro que perdura o problema de compreender como a linguagem permite a construção dos conceitos, pois a relação é naturalmente recíproca e a possibilidade de construir representações conceptuais é uma das condições necessárias para a aquisição da linguagem (1978, p. 285).
\end{abstract}

$\mathrm{Na}$ passagem dos esquemas sensório-motores para os esquemas conceituais, Piaget não deixa de outorgar a importância devida à linguagem, sobretudo na atividade de narrativa do sujeito; porém, a narrativa não explica a própria novidade construtiva da estrutura conceptual do pensamento, pois esta é produto da reorganização dos esquemas interiorizados (abstrações reflexivas). A narrativa, embora seja um intermediário indispensável como meio de evocação e de reconstituição, ela somente se inicia no limite superior da produção dos primeiros esquemas verbais, quando da produção dos primeiros "pré-conceitos" e transduções da criança.

Se a estrutura do pensamento não deriva da estrutura da linguagem, isso não leva a subestimar o papel da linguagem na construção de representações propriamente ditas. Por isso, Piaget, ao questionar-se sobre a passagem da linguagem ligada ao ato imediato e presente (primeiros esquemas verbais) para a construção de representações verbais propriamente ditas (de juízos de constatação e não mais apenas de juízos de ação), responde que a narrativa constitui um intermediário indispensável como meio de evocação e de reconstituição.

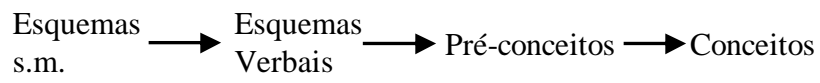
Narrativa

Após essas pesquisas, a convicção de Piaget se acentua na direção da irredutibilidade e indissociabilidade entre explicação endógena e exógena, o que se pode traduzir na fórmula seguinte:

Coordenação intra-individual (explicação endógena) $\longrightarrow$

Coordenação inter-individual (explicação exógena) $\longrightarrow$

O conceito e o juízo do indivíduo são produtos das transformações ocorridas no processo de interiorização dos esquemas e coordenação de esquemas de ação (esquemas verbais, preconceitos, transduções), o que envolve necessariamente reorganizações por abstrações reflexionantes. Como sabemos, a capacidade de classificação e ordenamento de assimetrias não se retira dos objetos exteriores, nem mesmo da sintaxe da linguagem, mas sim, das formas classificatórias e ordenadoras próprias às coordenações cada vez mais móveis e complexas dos esquemas sensório-motores. Nesse processo é evidente que a formação e acabamento da função simbólica é fundamental.

Esse processo de evolução interna não se opõe à evolução das próprias interações sociais. As relações interindividuais partem de relações centradas nas ações particulares para coordenações descentradas, dos pontos de vista de relações unilaterais de coação intelectual e de coação moral para relações de reciprocidade e de cooperação propriamente dita. A evolução da ação do indivíduo depende da evolução das relações nas quais este se encontra inserido, e isso reciprocamente. Nessa evolução a idéia de socialização se encontra intimamente relacionada com a cooperação: socializar significa compartilhar noções e signos com uma comunidade de falantes e ao mesmo tempo distingui-los das próprias idiossincrasias e dos pontos de vista particulares.

Da análise do movimento construtivo interno, realizada nas décadas de 1930 e 1940, não se pode deduzir que Piaget abandone a explicação social realizada na década de 1920 , pelo contrário, ele a leva em consideração, mas num nível de integração e diferenciação maior: solidariedade dos processos internos e externos, enquanto aspectos indissociáveis e irredutíveis da ação humana. Assim, é preciso perguntar-nos se a atribuição a Piaget de um determinismo biológico e insensibilidade à ação social, como insistem atualmente alguns dos seus críticos, não estará servindo somente para justificar a pertinência atual do reducionismo social que ele mesmo se encarregou de abandonar?

\section{ESTUDOS PIAGETIANOS APÓS A DÉCADA DO TRINTA E QUARENTA}

Uma vez descoberta a origem do pensamento e da função simbólica no esquematismo sensóriomotor, assim como o desenvolvimento posterior do pensamento e da linguagem na criança, Piaget tratará de formular melhor essas descobertas através de análises e estudos sobre as relações existentes entre lógica, linguagem e pensamento. Com esse intuito tratará também de diferenciar a sua tese, o mais explicitamente possível, das hipóteses e concepções epistemológicas concorrentes (empiristas, positivistas e pré-formistas) e dos reducionismos sociais. 


\section{Pesquisas junto a portadores de deficiências}

Recorrendo a pesquisas efetuadas por colaboradores junto a surdos, Piaget conclui que, apesar do atraso apresentado por esses sujeitos no que diz à formação das operações mentais, não se pode falar de carência da operação propriamente dita, pois nesses sujeitos se encontram os mesmos estágios de evolução, com um atraso de um ou dois anos em relação às crianças normais.

Pesquisas com cegos de nascença mostram atrasos de até quatro anos. Isso significa que a coordenação verbal não é suficiente para compensar o atraso da adaptação e coordenação dos esquemas sensóriomotores. Para esses sujeitos, certamente é necessária toda uma aprendizagem da ação sensório-motora para alcançar a constituição das operações comparáveis aos normais e até mesmo aos surdos-mudos.

No Brasil, as pesquisas junto a crianças surdas, na perspectiva piagetiana, iniciam-se com os trabalhos de Maria Alicia Ferrari de Zamorano (1983), orientada pela professora Zélia Ramozzi Chiarotino, do Instituto de Psicologia da USP. A esses trabalhos se seguiram as pesquisas realizadas por Rosimar Bortolini Pocker (1995, 2000), do Departamento de Educação Especial da UNESP - Campus de Marília.

De acordo com Piaget, se as crianças, alcançadas a representação e a função simbólica, não exercitarem a evocação e reconstituição das ações vividas, através das narrativas, não haverá possibilidade de que os esquemas se interiorizem e se transformem em conceitos. Para isso é necessário que elas estejam inseridas em permanente troca simbólica (exprimir e trocar, com outras crianças e adultos, lembranças, projetos, pensamentos e sentimentos). As crianças surdas, embora consigam organizar o mundo no plano sensório-motor, no plano simbólico ou semiótico, devido a danos produzidos nos canais auditivos, apresentam dificuldades ou limitações na continuidade da troca com o meio. Em função disso, o ritmo de formação do pensamento operatório fica prejudicado. Essas crianças conseguem constituir a forma de pensamento operatório elementar, mas com atrasos significativos em relação aos ouvintes.

As pesquisas de Pocker (1995, 2001), no contexto escolar, junto a esse tipo de crianças, mostram problemas derivados do ensino da língua de sinais e da linguagem verbal. Essa autora mostra que, embora a linguagem de gestos seja o elemento natural para a comunicação dessas crianças, nem sempre é utilizada enquanto instrumento verdadeiro de troca simbólica, pois a comunicação se reduz a sua mínima expressão enquanto expressão do pensamento. A própria linguagem verbal, quando adquirida, não é usada com esse intuito, mas simplesmente como instrumento de instrução e treino das suas performances cognitivas e lingüísticas. Os trabalhos de reeducação realizados por essa autora mostram a pertinência das hipóteses de partida, assim como possibilidades de uma educação ativa.

Por outro lado, trabalhos realizados por nós, na década de oitenta, junto a crianças de favela, mostram problema análogo em crianças surdas e, por isso mesmo, corroboram a validez da tese piagetiana no que se refere ao prolongamento, com reconstrução, do esquematismo sensório-motor, na formação do pensamento conceitual. Mostram também a necessidade da troca simbólica, como meio de reconstituição do vivido e interação de pontos de vista, no processo de construção interna do indivíduo.

\section{Pesquisas psicolinguiísticas sobre aprendizagem da sintaxe e a operação mental}

Por outro lado, trabalhos de lingüistas, colaboradores de Piaget, que comparam aprendizagem de expressões sintáticas de crianças operatórias e préoperatórias, mostram que a utilização de expressões lingüísticas não modifica, necessariamente, as suas noções conceptuais, se estas não se encontram sensíveis a essa transformação.

Essas pesquisas, em especial aquelas realizadas por H. Sinclar (1967) e E. Ferreiro (1971), corroboram os resultados das pesquisas realizadas no período anterior, no sentido de que a linguagem não constitui a fonte da organização lógica do pensamento, e que, justamente, essa lógica deveria se buscar na coordenação geral das ações, a partir dos níveis sensório-motores.

No meio brasileiro, a pesquisa concluída por Inaiara Rodrigues (2000) sobre o desenvolvimento da noção temporal por meio da narrativa oral segundo a teoria piagetiana, e aquela em fase de conclusão (tese de doutorado), analisam questões psicolingüísticas a partir da relação entre narrativa e noção temporal em crianças normais e crianças com problemas de aprendizagem.

\section{A PROPÓSITO DA CRÍTICA ÀS CORRENTES EMPIRISTAS E POSITIVISTAS CONTEMPORÂNEAS: TESES CONCLUSIVAS}

É evidente que a conduta humana é social desde o nascimento e que a pressão social cumpre uma 
influência decisiva no desenvolvimento e na socialização do pensamento humano; porém explicar esse desenvolvimento a partir da ação coletiva, sem levar em conta a atividade estruturante do indivíduo, é fazer opção por um dos pólos da relação (indivíduo meio social), como o fazem o positivismo e o reducionismo sociológico. Com efeito, a partir de novos dados acumulados, Piaget faz a crítica a essas concepções.

Segundo Piaget, para certas concepções, a lógica inerente ao sistema da língua constitui não somente um fator essencial - ou mesmo único - de aprendizagem da lógica pela criança ou por um indivíduo qualquer, mas ainda fonte de toda a lógica da humanidade inteira. Assim, segundo o positivismo lógico, a lógica dos lógicos não é outra coisa que não uma síntaxe e uma semântica generalizadas.

Destarte, para o positivismo lógico, antes da aquisição da linguagem não existe uma organização lógica no pensamento do indivíduo. Essa forma de pensamento explica-se pela aquisição da sintaxe lingüística por parte da criança, a qual, ao interiorizarse, transforma o pensamento inicial da criança. Em conseqüência, a explicação da novidade se encontra numa fonte exterior ao próprio processo evolutivo do pensamento pré-verbal.

Como se pôde observar nos itens anteriores, as pesquisas de Piaget das décadas de 1930 e 1940 mostram, claramente, que as raízes do pensamento encontram-se nos esquemas de ação, os quais já prefiguram, no seu funcionamento e nas suas estruturações mais complexas, formas isomorfas às futuras estruturas do pensamento infantil e do adulto. A defesa dessa tese não se reduz à análise dessa isomorfia, mas estende-se ao levantamento de dados novos e à explicação da formação da função simbólica e do processo de transformação dos primeiros esquemas verbais em conceitos propriamente ditos.

Contrariamente ao empirismo e ao positivismo lógico, observa-se, na formulação de Piaget, uma verdadeira construção endógena dos conceitos. É óbvio, pelo que foi dito anteriormente, que essa construção não se realiza de maneira solipsista, à margem da interação com os outros indivíduos. Pelo contrário, essa interação é condição necessária, embora não suficiente. Já observamos a ação imprescindível da narrativa na passagem dos esquemas sensório-motores para os conceitos, assim como o avanço solidário da organização lingüística e da organização conceitual.

Se o estado alcançado pelo pensamento conceitual não é da mesma natureza que a dos esquemas sensório- motores - pois são estruturas completamente diferentes no que diz respeito à mobilidade e amplitude de ação, e mesmo de interação social -, isso não elimina a continuidade do funcionamento, pois a adaptação num novo plano, o da representação e da socialização, responde aos mesmos mecanismos do plano anterior (sistemas de totalidade, adaptação enquanto solidariedade entre assimilação e acomodação, generalização construtiva, abstração reflexionante, etc.). Por isso, para Piaget, a tese teórica maior para explicar a evolução do comportamento humano, incluídas a inteligência e a linguagem, é da continuidade com reconstrução das estruturas anteriormente adquiridas. Entretanto, isso não significa o abandono da necessária ação das relações sociais na formação do pensamento conceitual; pelo contrário, para ele, permanece a explicação da evolução do pensamento em função das interações sociais, como nas suas teses iniciais, mas na condição de permanecer garantida a atividade de processos internos e a continuidade, com reconstrução, de conquistas anteriormente alcançadas. Isso conduz à formulação de uma tese de maior síntese integrativa entre as dimensões sociais e individuais: a evolução não responde a uma determinação unilateral, mas a uma solidariedade radical entre as coordenações interindividuais e as coordenações intra-individuais.

A possibilidade, então, de superar todas as formas de reducionismo exige postular novos paradigmas que possibilitem a relativização dos determinismos e exija pensar a evolução enquanto dialética de continuidade e descontinuidade nos diferentes planos da vida biológica, psicológica e social e da solidariedade entre as coordenações intra-individuais e as coordenações interindividuais. É essa a direção que tomam os esforços teóricos e experimentais de Piaget.

\section{REFERÊNCIAS}

Banks-Leite, L. (1997). As questões lingüísticas na obra de Piaget: apontamentos para uma reflexão crítica. Em L.Banks-Leite (Org.). Percursos piagetianos (pp.207-223). São Paulo: Cortez.

Bronckart, J. P. (2000). El problema de la consciência como "analizador" de las epistemologías de Vygotsky y de Piaget. Em E. Serrat, S. Aznar, (Org.). Piaget y Vigotski ante el siglo XXI: referentes de actualidade (pp.15-41). Girona: Horsori.

Dongo Montoya, A. O. (1998a, set./out.). L'image mental et la construction de la pensée chez l'enfant. Bulletin de Psychologie, 51(5), 529-535.

Dongo Montoya, A. O. (1998b). Representação imagética e construção do conhecimento na criança. Tese (Livre 
Docência). Faculdade de Filosofia e Ciências, Universidade Estadual Paulista Júlio Mesquita Filho, Marília.

Dongo Montoya, A. O. (2005). Piaget: imagem mental $e$ construção do conhecimento. São Paulo: EDUNESP.

Ferreiro, E. (1971). Les relations temporelles dans le langage de l'enfant. Geneve: DROZ.

Piaget, J. (1924). Le jugement et le raisonnement chez l'enfant. Paris: Delachaux et Niestlé.

Piaget, J. (1936).La naissance de líntellgence chez l'enfant. Paris: Delachaux et Niestlé.

Piaget, J. (1969). A explicação em Psicologia e o paralelismo psico-fisiológico. Em P. Fraisse, J. Piaget. Tratado de Psicologia Experimental. (Vol.1) (pp.121-152) Rio de Janeiro: Forense.

Piaget, J. (1978). A formação do símbolo na criança: imitação, jogo e sonho, imagem e representação. Rio de janeiro: Guanabara-Koogan.

Piaget, J. (1999). O pensamento e a linguagem na criança. São Paulo: Martins Fontes.

Pocker, R (1995). A aquisição dos métodos de ensino de surdo e desenvolvimento cognitivo. Dissertação de Mestrado NãoPublicada. Programa de Pós-Graduação em Educação Especial, Universidade Estadual Paulista Júlio de Mesquita Filho, Marília.
Pocker, R. (2001). Troca simbólica e desenvolvimento cognitivo em crianças surdas: uma proposta de intervenção educacional. Tese de Doutorado NãoPublicada. Programa de Pós-Graduação em Educação Especial, Universidade Estadual Paulista Júlio de Mesquita Filho, Marília.

Rodrigues, B. I. (2000). Desenvolvimento da noção temporal por meio da narrativa oral segundo a teoria piagetiana. Dissertação de Mestrado Não-Publicada. Programa de PósGraduação em Ensino-Aprendizagem, Universidade Estadual Paulista Júlio de Mesquita Filho, Marília.

Sinclar, H. (1967). Acquisition du langage et developpment de la pensée. Paris: DUNOD,

Vygotsky, L. S. (1991). Pensamento e linguagem. São Paulo: Martins Fontes.

Zamorano, M. A. (1983). Um estudo sobre o papel da linguagem oral, através de provas piagetianas, no pensamento da criança surda. Dissertação de Mestrado Não-Publicada. Programa de Pós-Graduação em Psicologia Escolar, Universidade de São Paulo, São Paulo.

Recebido em 23/02/2005 Aceito em 06/08/2005

Endereço para correspondência: Adrián Oscar Dongo Montoya. Avenida Gonçalves Dias, 34, Apto. 404, CEP 17.501-030 Marília-SP.E-mail: adrian@wnet.com.br 